\title{
Sex Hormone-Binding Globulin Deficiency
}

National Cancer Institute

\section{Source}

National Cancer Institute. Sex Hormone-Binding Globulin Deficiency. NCI Thesaurus.

Code C120373.

Subnormal concentration of the glycoprotein, sex hormone-binding globulin (SHBG), the primary transport protein for androgens and estrogens in serum, resulting in reduced concentrations of total sex steroids, but minimal change in concentrations of free sex steroids. 